\title{
The Empirical Evidence Conclusively Supports Global Investing
}

Janna Khoroujik, California State University

Hamid Z. Ahmadi, (Email: ahmadih@csus.edu), California State University

\begin{abstract}
Although there still exits a sense of uneasiness in the stock market about global investing, the above average rate of returns and steady growth of international companies for the past ten years compels prudent investor to invest abroad. The main goal of this work is to examine the performance of foreign companies and compare their risk-adjusted returns to the returns of the US companies. In this process we selected the foreign companies that have been accepted by our financial market and traded in the US as ADR (American Depository Receipts) in NYSE or NASDAQ. Additionally, we have considered only those ADRs that had high volume and outperformed the industry index. Specifically, this study is going to address whether the performance of a global portfolio meets or surpasses the performance of a diversified domestic portfolio. More importantly the emphasis of this work is to determine whether the global portfolios consistently and significantly outperformed the US equity portfolios. The asset selection and the optimization process applied to domestic and international portfolios are identical to maintain consistency and comparability of the results. For each portfolio we used the 2003-2004 daily observations to optimize allocations and we used the 2005-2006 data to evaluate the performance of each portfolio.
\end{abstract}

\section{INTRODUCTION}

1

gove rnance and inconsistencies in financial reporting or accounting practices. In spite of these concerns, investor apprehensions should have been eased by the introduction and growing popularity of ADRs (American Depositary Receipts) because these are securities that are traded like U.S. stocks, obey U.S. disclosure rules and follow U.S. Security Exchange Commission (SEC) regulations. However, studies by Aheame, Griever and Warnock (2004), Dahlquist, Pinkowitz, Stuls and Williams (2003), and Edison and Warnock (2004) show the home bias still prevails.

In this work we have evaluated the performance of foreign companies and matched their performance against that of similar companies in U.S. The results were striking. We found that the annualized risk-adjusted rate of return for our portfolio of ADRs was 13.7 percent higher than that of our domestic portfolio. Yet it remains unclear whether such a superior rate of return would be enough to sway home-biased portfolios toward more balanced global ones.

We screened 2,175 ADRs and selected those that were comparable to U.S. companies in terms of capitalization, liquidity, return on equity, and other financial characteristics. Then, we collected daily prices as well as stock and cash dividend data from March 2003 to September 2006 for ADRs and comparable U.S. companies. To ensure comparability of returns, we used the Risk Adjusted Managed Portfolio (RAMP) optimization model, which includes algorithms to adjust and standardize foreign investment return for currency and market risks.

\section{INCENTIVES TO BE REGISTERED IN U.S. STOCK EXCHANGES}

There is a common belief that the U.S. is a launching pad for successful and profitable entities. This may be true for international actors, artists, and especially rock and roll bands, but it does not seem to be the case for many 
sound foreign companies in the 'U.S. equity markets'. Nonetheless, being listed as an ADR on a U.S. exchange brings prestige to the foreign company and considerably improves its credit rating worldwide. Such a listing not only opens opportunities to profit from the active U.S. market but also helps the company raise capital globally.

The history of ADRs goes back as far as 1927, when J.P. Morgan created and launched the very first ADR for a famous British retailer, Selfridges Provincial Stores Limited. Now, almost 80 years later, the ADR market has grown to nearly 2500 issuers from more than 75 countries with more than $\$ 600$ billion in market capitalization.

Trading directly with overseas markets was virtually impossible in the early days of stock markets and numerous inefficiencies in trading foreign assets still exist today. Complex currency conversions, unreliable transaction services, and poor information flow are some of the reasons why U.S. investors shy away from ADRs. Nonetheless, as more multinational companies become available through ADRs, U.S. investors are feeling more comfortable considering them as a vehicle for diversification.

Trading ADRs is essentially the same as trading shares of any U.S. company in a domestic equity market. They are traded in U.S. Dollars but represent an interest in shares of a foreign company. Purchasing ADRs is the same as purchasing the shares directly in a foreign market with fewer restrictions and in a more convenient manner.

ADRs are divided in two major categories - sponsored and unsponsored. Unsponsored ADRs are similar to the private arrangements between investors and brokers-dealers. It is important to note that, in this case, the foreign company is not a party to an ADR agreement. These shares are traded in over-the-counter (OTC) markets and do not comply with regulatory requirements of the Securities and Exchange Commission (SEC). While most foreign companies are looking to raise capital in the U.S., the demand for unsponsored ADRs in the U.S. financial markets is shrinking. On the other hand, sponsored ADRs, which are jointly established between the issuer and a depositary bank under depository agreement, are increasing. Most ADRs that are listed today on various U.S. stock exchanges are sponsored and do comply with the SEC regulations.

ADRs are inherently risky. In other words, bad information, currency risk, and political and economic uncertainties, among other factors, add to the unpredictability of a foreign investment's returns. Nonetheless, the increased availability of information over the Internet and instant execution of market orders through Internet accounts significantly increased the demand for foreign investment in recent years. Also, investors realize that purchasing ADRs facilitates diversification and enhances the performance of their portfolios.

\section{LITERATURE REVIEW}

Schaub (2006) studied the short run performance of ADRs and his findings indicate that a sample of 100 ADRs, which included ADRs from both developed and emerging markets, significantly outperformed the NASDAQ

Index. However, the emerging market ADRs alone underperformed the NASDAQ Index by nearly 9 percent, whereas developed market ADRs outperformed the same index by more than 7.5 percent.

Schaub and Highfield (2006) examined the long-term returns of ADRs from 1987 to 2000 and concluded that, prior to 1998, ADRs underperformed U.S. markets. However, after 1998 ADRs outperformed the U.S. markets. The results of this study also show that the performance of emerging market ADRs is very sensitive to market timing, whereas the performance of developed market ADRs is not as responsive.

A study by Foerster and Karolyi (2000) suggests that firms that issue ADRs on major public exchanges in the U.S. have higher overall returns. Also Kao, Wei, and Vu, (1991) found that an internationally diversified portfolio of ADRs outperformed both a U.S. stock market index and a global stock market index on a risk-adjusted basis. In support of diversification, Fang and Loo (2002) found that the performance of ADRs traded in the U.S. securities markets was not affected by U.S. market movements, but rather was significantly correlated with the foreign (home) market indices. 


\section{DATA AND SELECTION CRITERIA}

In this study, our goal is to evaluate the performance of two distinct portfolios - one composed of U.S. stocks and one composed entirely of ADRs. The components of each portfolio, albeit different, were selected based on a thorough analysis of individual assets. The selection of the assets for either portfolio was exhaustive relying on various reputable data sources reporting financial characteristics of each stock. The list of ADRs was obtained directly from the leading depository bank, the Bank of New York, which has tracked, 2,175 ADRs since 1982. This source initially helped us to filter out low volume ADRs that are traded at the national exchanges. We further screened the remaining ADRs by Morningstar and StockScouter ratings to include only the high quality U.S. and foreign companies.

The specific criteria for selecting an asset in either of the portfolios, domestic or international, are volume, $\mathrm{P} / \mathrm{E}$ ratio, return on equity, positive returns and data sufficiency. One of the most important indicators for liquidity is volume of trade. Low volume signals the possibility of sudden price movements due to a small shift in demand for that stock. Thus, we considered ADRs with large trading volume to avoid daily "wild" swings in security prices. Needless to say, high trading volume of an ADR in the U.S. markets indicates the maturity of the company and its products. Therefore, the 50 ADRs with the highest 200-day average volumes were included in our ADR portfolio.

We compared the return on equity (ROE) of each ADR with the ROE of its industry, selecting only those ADRs that outperformed the industry. Companies with unusually high P/E ratios and those with missing P/E data were excluded.

Finally, we computed the average monthly returns for both portfolios from March 2003 to September 2006 and considered companies with positive returns. Companies that were listed after March 2003 were eliminated due to the insufficient number of observations.

Table 1 below shows the breakdown of the selection criteria for both portfolios.

Table 1: Summary Of Selection Criteria

\begin{tabular}{|c|c|c|}
\hline Criteria & ADR & U.S. Stocks \\
\hline Average Daily Volume & 1.10 Million -6.30 Million & 1.11 Million -5.67 Million \\
\hline P/E Ratio & $6.4-43.2$ & North America \\
\hline Continents & Europe (8), Latin America (8), Asia (4) & U.S \\
\hline Countries & 14 & 19 \\
\hline Industries & 15 & 8 and higher (10 being the best) \\
\hline StockScouter & 5 and higher (10 being the best) & D and lower (A being the best) \\
\hline Ownership Grade & D and lower (A being the best) &
\end{tabular}

StockScouter ranks each company from 1 to 10, with 10 indicating best performance. We selected ADRs rated 5 or higher and U.S. stocks rated 8 and higher. In addition, we considered StockScouter 'Ownership Ratings', which range from $\mathrm{A}$ to $\mathrm{F}$, and eliminated stocks that were rated $\mathrm{F}$. The $\mathrm{F}$ rating indicates the possibility that executives or Board members are exercising their sell options. Below are two tables that show the complete list of ADRs and U.S. stocks that passed all screening criteria and were included in our portfolio analysis.

The above process ensures application of similar criteria to both foreign and U.S. stocks and includes only well established companies with solid records. Also Tables 2 and 3 show that these two portfolios are widely diversified among industries and countries. 
Table 2: ADR Portfolio

\begin{tabular}{|c|c|c|c|}
\hline Ticker & Name & Industry & Country \\
\hline AAUK & Anglo American plc & Gold & United Kingdom \\
\hline $\mathrm{ABB}$ & ABB Ltd & Industrial Electrical Equipment & Switzerland \\
\hline AMX & America Movil S.A. de C.V & Wireless Communications & México \\
\hline ASML & ASML Holding N.V. & $\begin{array}{c}\text { Semiconductor Equipment \& } \\
\text { Materials }\end{array}$ & The Netherlands \\
\hline BHP & BHP Billiton Limited & Industrial Metals \& Minerals & Australia \\
\hline $\mathrm{CX}$ & Cemex S.A. B de C.V. & Cement & México \\
\hline ERIC & $\begin{array}{c}\text { Telefonaktiebolaget LM } \\
\text { Ericsson }\end{array}$ & Communication Equipment & Sweden \\
\hline GGB & Gerdau S.A. & Steel \& Iron & Brazil \\
\hline GSK & GlaxoSmithKline plc & Drug Manufacturers - Major & United Kingdom \\
\hline INFY & Infosys Technologies Limited & Technical \& System Software & India \\
\hline MBT & Mobile TeleSystems OJSC & Wireless Communications & Russia \\
\hline NTES & NetEase.com, Inc. & Internet Information Providers & China \\
\hline PBR & Petroleo Brasileiro S.A. & $\begin{array}{l}\text { Oil \& Gas Drilling \& } \\
\text { Exploration }\end{array}$ & Brazil \\
\hline RIO & Companhia Vale do Rio Doce & Steel \& Iron & Brazil \\
\hline SAP & SAP AG & Application Software & Germany \\
\hline SNY & sanofi-aventis & Drug Manufacturers - Other & France \\
\hline SPIL & Siliconware Precision Industries & $\begin{array}{c}\text { Semiconductor Equipment \& } \\
\text { Materials }\end{array}$ & Taiwan \\
\hline TMX & Telefonos de Mexico, S.A. & Telecom Services - Foreign & México \\
\hline TS & Tenaris S.A. & Steel \& Iron & Argentina \\
\hline TV & Grupo Televisa, S.A. & Broadcasting - TV & México \\
\hline
\end{tabular}

Table 3: U. S. Portfolio

\begin{tabular}{|c|c|c|}
\hline Ticker & Name & Industry \\
\hline ABI & Applied Biosystems Group, Applera Corp & Scientific \& Technical Instruments \\
\hline AEOS & American Eagle Outfitters & Apparel Stores \\
\hline AMTD & TD Ameritrade Holding Corp. & Investment Brokerage - National \\
\hline ANF & Abercrombie \& Fitch Co. & Apparel Stores \\
\hline BBY & Best Buy Co., Inc. & Railroads \\
\hline BNI & Burlington Northern Santa Fe Corporation & Farm \& Construction Machinery \\
\hline CAT & Caterpillar Inc. & Business Software \& Services \\
\hline CTSH & Cognizant Technology Solutions Corp. & Copper \\
\hline FCX & Freeport-McMoRan Copper \& Gold Inc. & Beavy Construction \\
\hline GENZ & Genzyme Corporation & Oil \& Gas Drilling \& Exploration \\
\hline GLBL & Global Industries, Ltd. & Communication Equipment \\
\hline GW & Grey Wolf, Inc. & Application Software \\
\hline MOT & Motorola, Inc. & General Building Materials \\
\hline ORCL & Oracle Corporation & Asset Management \\
\hline SHW & Sherwin-Williams Company & Electric Utilities \\
\hline TROW & T. Rowe Price Group, Inc. & Drug Manufacturers - Major \\
\hline TXU & TXU Corporation & Major Integrated Oil \& Gas \\
\hline WYE & Wyeth & Restaurants \\
\hline XOM & Exxon Mobil Corporation & Yum! Brands, Inc. \\
\hline YUM & &
\end{tabular}

\section{THE MODEL}

There are three common approaches to portfolio optimization - the Equal Weights (EW) approach, the Minimum Variance Portfolio (MVP) approach, and the Modern Portfolio Theory (MPT) approach. While each of 
these methods can help a portfolio manager respond to his clients' needs, there is an additional approach that can be used to generate an optimal portfolio - the Risk-Adjusted Managed Portfolio (RAMP) model. While the MVP and MPT approaches rely on variance to determine risk and help portfolio managers determine whether to buy or sell a particular asset, RAMP considers beta and variance. Specifically, RAMP is a two-stage model that provides us with a simple, but effective means of selecting stocks and determining the appropriate proportions of each to hold in our portfolio. The first stage of the RAMP model uses the Treynor Index to help us select stocks for our portfolio, while the second stage uses the Sharpe Index to determine what proportion of our portfolio should be invested in each stock.

\section{Stage 1 -Stock Selection}

Since we need to determine which stocks to include in our optimal portfolio, the first stage of the RAMP model assists us with stock selection. Of course, it would be very easy to form such a portfolio if there were a single number we could use to decide whether or not to include a particular stock in the portfolio. The RAMP optimization model finds this key number and tells us to include in our portfolio any stock with a Treynor Index that exceeds it.

TreynorIndex $=\frac{\left(R_{j}-R_{f}\right)}{\beta_{j}}$

Where $R_{j}$ is the rate of return for stock " $\mathrm{j}$," $R_{f}$ is the risk-free rate of return and $B_{j}$ is the beta value for stock " $\mathrm{j}$ ". Note that both the market rate of return $\left(R_{m}\right)$ and the risk-free rate of return $\left(R_{f}\right)$ result from general stock market fluctuations and are not due to the work of a portfolio manager. In other words, $\left(R_{m}-R_{f}\right)$ is the return of an "unmanaged portfolio". If the Treynor Index $\frac{\left(R_{j}-R_{f}\right)}{\beta_{j}}$, which is the risk-adjusted return of stock $j$, is greater than $\left(R_{m}-R_{f}\right)$, then stock $\boldsymbol{j}$ outperformed the unmanaged market portfolio and stock $\boldsymbol{j}$ is a candidate to be included in our optimal portfolio. Once again, the general rule for including or excluding stocks from our optimal portfolio is to include the stock if its Treynor Index is greater than the key number calculated by RAMP. We will call this key number the cut-off number.

\section{Stage 2 - Determining Optimal Proportions}

Inclusion and exclusion of stocks is the first part of the RAMP model. The second task is to find the proportions to be invested in each included stock in order to create an optimal portfolio. This optimization process is similar to MPT in that the proportions of the market portfolio, or Portfolio M, are determined by maximizing the slope of the Capital Market Line (CML). In other words, we hold stocks in the proportions dictated by the maximum Sharpe Index.

In summary, the RAMP model compares a stock's risk-adjusted return (as measured by the Treynor Index) with the cut-off number mentioned above to determine whether to include the stock in our portfolio. It then uses the Sharpe Index to find the proportion of funds to be invested in each stock in order to create an optimal portfolio. Thus, the optimal portfolio we select using the RAMP model will not only have passed the Treynor Index test, but will also have secured the highest possible return at any given level of risk.

\section{Rebalancing}

An investor must also pay close attention to rebalancing, which is the periodic adjustment of the proportion of the portfolio invested in each asset. Rebalancing is a means of maintaining the optimal asset mix within the portfolio through purchase and sale of individual assets. After an investor decides how to allocate his or her assets, the decision as to what portfolio rebalancing strategy to use is probably the most important factor in creating and maintaining a successful portfolio. As the economic environment and market conditions change, investors must rebalance their portfolios to incorporate current and relevant information into their asset allocation processes. 
So how often a portfolio should be rebalanced? The answer to this question is partially subjective and partially determined by factors such as the type of investment strategy and the amount of work required of portfolio managers in the rebalancing process. In general, we can distinguish between the following two approaches to portfolio rebalancing:

1. Calendar Rebalancing: Rebalancing the portfolio to its optimal allocation at a certain frequency such as weekly, biweekly, monthly, quarterly, etc.

2. Threshold Rebalancing: Rebalancing the portfolio to its optimal allocation once it exceeds a certain range. For example, the portfolio could be rebalanced when the portfolio weights differ by more than ten percent from the optimal weights.

\section{Parameters}

Our data consists of daily observations from March 2003 to September 2006. We split the data into two parts: 1) observations from March 2003 to September 2005; and 2) observations from September 2005 to September 2006. The first part is used to compute inputs for the RAMP optimization model and the second part is used to track the performance of the portfolios each month.

As mentioned above, the RAMP model includes a stock if its Treynor Index is greater than a cut-off number. One of the inputs to the Treynor Index is the risk-free rate and in this study we use an aggregate rate of 3 percent for this parameter. Also, we selected the option to pay 2 percent money market rate to the unused cash in the account.

\section{RESULTS}

The results of our study show that from September 2005 to September 2006, on average, the return of the ADR portfolio was 20.96 percent higher than the return of the S\&P 500. Furthermore, during this period, on average, the return of the ADR portfolio was 14.3 percent higher than the return of the portfolio formed by including only U.S. stocks.

Charts 1 and 2 show the asset allocation output of the RAMP optimization model. Chart 1 indicates the proportions invested in each ADR, while Chart 2 illustrates the proportions invested in each U.S. stock. Note that not all ADRs or U.S. stocks were selected and that a few have small investment proportions.

\section{Chart 1: Selected ADRS (11 out of 20 ADRs)}

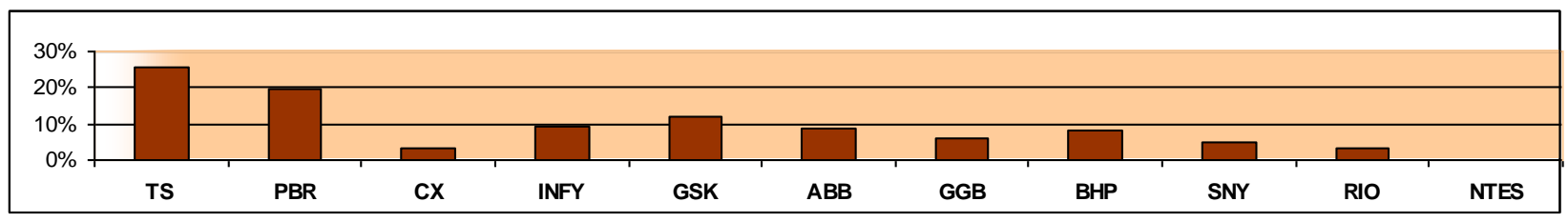

\section{Chart 2: Selected U.S. Stocks (14 out of 20 Stocks)}

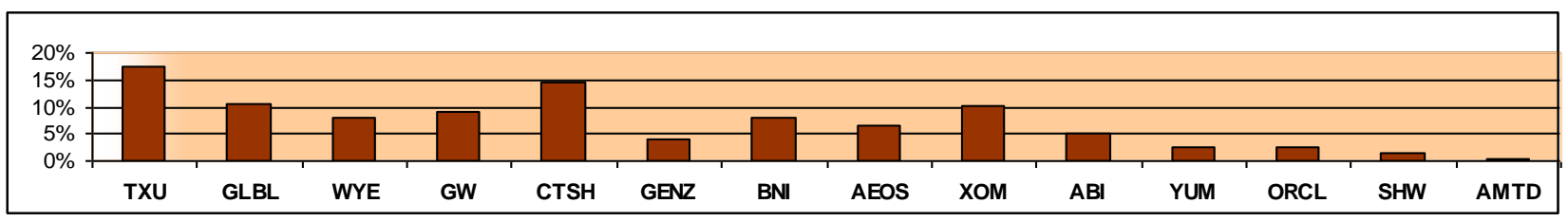


The performance of each portfolio, along with the performance of the stock market ( $\&$ \& 500), is presented in Graph 1 below. This graph displays the performance of portfolios formed by the RAMP model for both U.S. stocks and ADRs. The results clearly demonstrate that the portfolio of ADRs significantly outperformed the portfolio of U.S. stocks alone. In addition, Graph 1 illustrates that both portfolios considerably outperformed the return of the S\&P 500 , indicating that the portfolios formed by the RAMP model outperformed the stock market's benchmark.

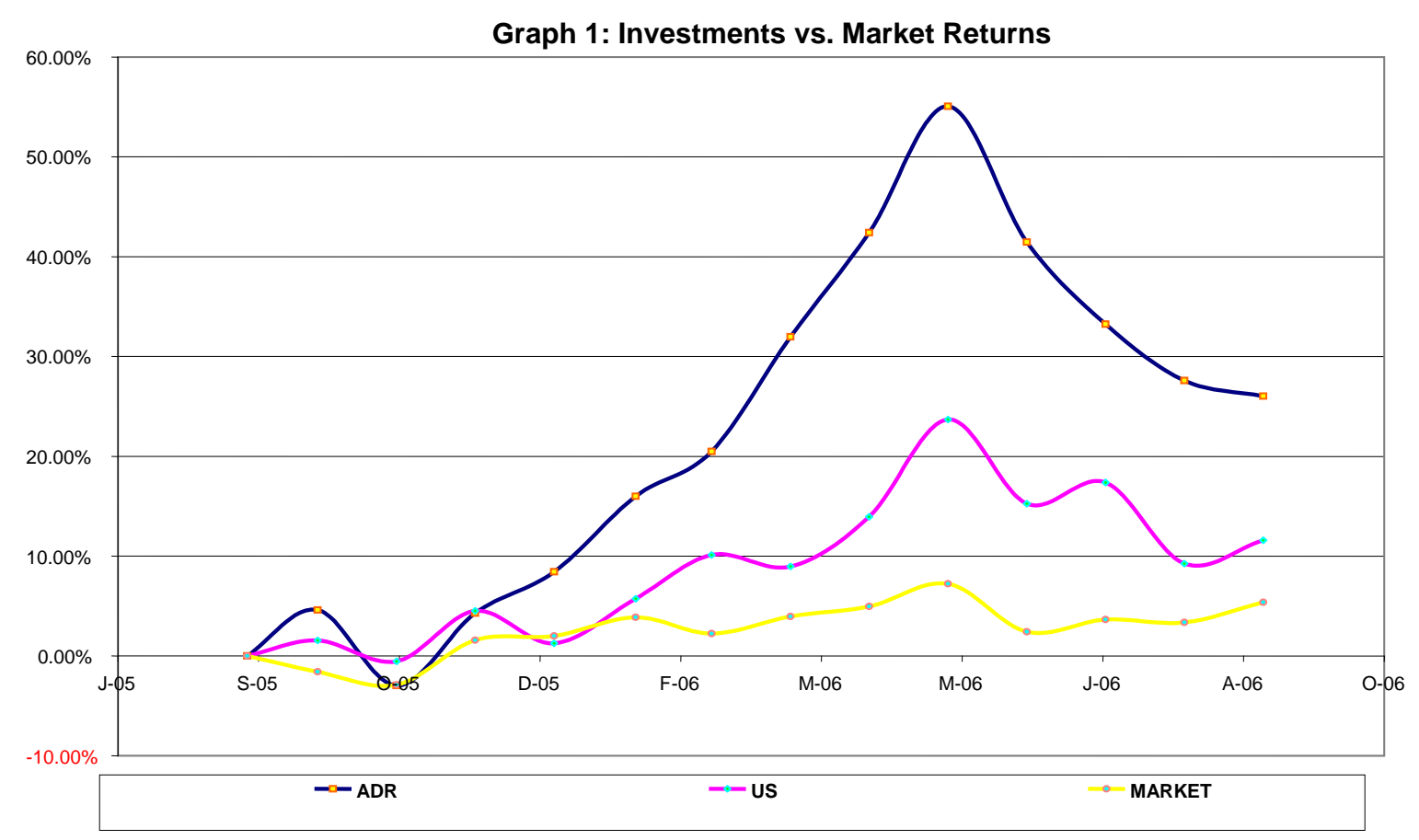

It is important to note that the returns of ADR and U.S. portfolios are standardized and adjusted for risk to make comparisons possible. That is, the graph above reports the risk-adjusted returns for all portfolios so that a portfolio's performance can be compared with the performance of other portfolios and the stock market.

Table 4, shows the proportions of investment in each industry, country and company. This table shows that, in September 2005, the RAMP model selected the identified ADRs based on the data from March 2003 to September 2005. It is worth noting that the model suggests that only 20 percent of a portfolio should be invested in European companies and the rest should be invested in the emerging or developing countries.

Table 5, shows the proportions of investment in each U.S. company and its corresponding industry. This table shows that, in September 2005, the RAMP model selected the following U.S. stocks based on the observations from March 2003 to September 2005.

The premise of this work is not to show the superiority or the weaknesses of the RAMP model. It is to examine the performance of ADRs and U.S. stocks. To make our results independent of any optimization model, we decided to test the results by using Equal Weight approach. That means we assigned equal weight to each ADR to form an international portfolio and equal weights to U.S. stocks to form a domestic portfolio. 
Table 4: ADRs By RAMP Model

\begin{tabular}{|c|l|c|c|l|c|}
\hline Ticker & \multicolumn{1}{|c|}{ Name } & Proportion & Country & \multicolumn{1}{|c|}{ Industry } & Exchange \\
\hline TS & Tenaris S.A. & $25.6 \%$ & Argentina & Steel \& Iron & NYSE \\
\hline PBR & Petroleo Brasileiro S.A. & $19.6 \%$ & Brazil & $\begin{array}{l}\text { Oil \& Gas Drilling \& } \\
\text { Exploration }\end{array}$ & NYSE \\
\hline CX & Cemex S.A. B de C.V. & $3.1 \%$ & México & Cement & NYSE \\
\hline INFY & Infosys Technologies Limited & $9.2 \%$ & India & Technical \& System Software & NASDAQ \\
\hline GSK & GlaxoSmithKline plc & $11.8 \%$ & United Kingdom & Drug Manufacturers - Major & NYSE \\
\hline ABB & ABB Ltd & $8.7 \%$ & Switzerland & Industrial Electrical Equipment & NYSE \\
\hline GGB & Gerdau S.A. & $5.9 \%$ & Brazil & Steel \& Iron & NYSE \\
\hline BHP & BHP Billiton Limited & $8.0 \%$ & Australia & Industrial Metals \& Minerals & NYSE \\
\hline SNY & sanofi-aventis & $4.7 \%$ & China & Drug Manufacturers - Other & NASDAQ \\
\hline RIO & Companhia Vale do Rio Doce & $3.3 \%$ & Brazil & Steel \& Iron & NYSE \\
\hline NTES & NetEase.com, Inc. & $0.2 \%$ & China & Internet Information Providers & NASDAQ \\
\hline
\end{tabular}

Table 5: U.S. Stocks By RAMP Model

\begin{tabular}{|c|l|c|l|}
\hline Ticker & \multicolumn{1}{|c|}{ Name } & Proportion & \multicolumn{1}{c|}{ Industry } \\
\hline TXU & TXU Corporation & $17.4 \%$ & Electric Utilities \\
\hline GLBL & Global Industries, Ltd. & $10.4 \%$ & Heavy Construction \\
\hline WYE & Wyeth & $8.0 \%$ & Drug Manufacturers - Major \\
\hline GW & Grey Wolf, Inc. & $9.2 \%$ & Oil \& Gas Drilling \& Exploration \\
\hline CTSH & Cognizant Technology Solutions Corp. & $14.6 \%$ & Business Software \& Services \\
\hline GENZ & Genzyme Corporation & $4.0 \%$ & Biotechnology \\
\hline BNI & Burlington Northern Santa Fe Corporation & $7.9 \%$ & Railroads \\
\hline AEOS & American Eagle Outfitters & $6.5 \%$ & Apparel Stores \\
\hline XOM & Exxon Mobil Corporation & $10.2 \%$ & Major Integrated Oil \& Gas \\
\hline ABI & Applied Biosystems Group, Applera Corp & $5.0 \%$ & Scientific \& Technical Instruments \\
\hline YUM & Yum! Brands, Inc. & $2.5 \%$ & Restaurants \\
\hline ORCL & Oracle Corporation & $2.5 \%$ & Application Software \\
\hline SHW & Sherwin-Williams Company & $1.5 \%$ & General Building Materials \\
\hline AMTD & TD Ameritrade Holding Corp. & $0.4 \%$ & Investment Brokerage - National \\
\hline
\end{tabular}

Using the Equal Weight approach, we found that from September 2005 to September 2006, on average, the return of the ADR portfolio was 20.62 percent higher than the return of the S\&P 500 and the return of the ADR portfolio was 12.87 percent higher than the return of a portfolio of only U.S. stocks.

The performance of each portfolio, along with the performance of the domestic stock market (the S\&P 500), is presented in the Graph 2. This graph shows the performance of portfolios formed by the Equal Weight approach for both U.S. stocks and ADRs. Once again, the results clearly demonstrate that the portfolios of ADRs significantly outperformed the portfolios of U.S. stocks alone. 
Graph 2: Equal Weight Investments vs. Market Returns

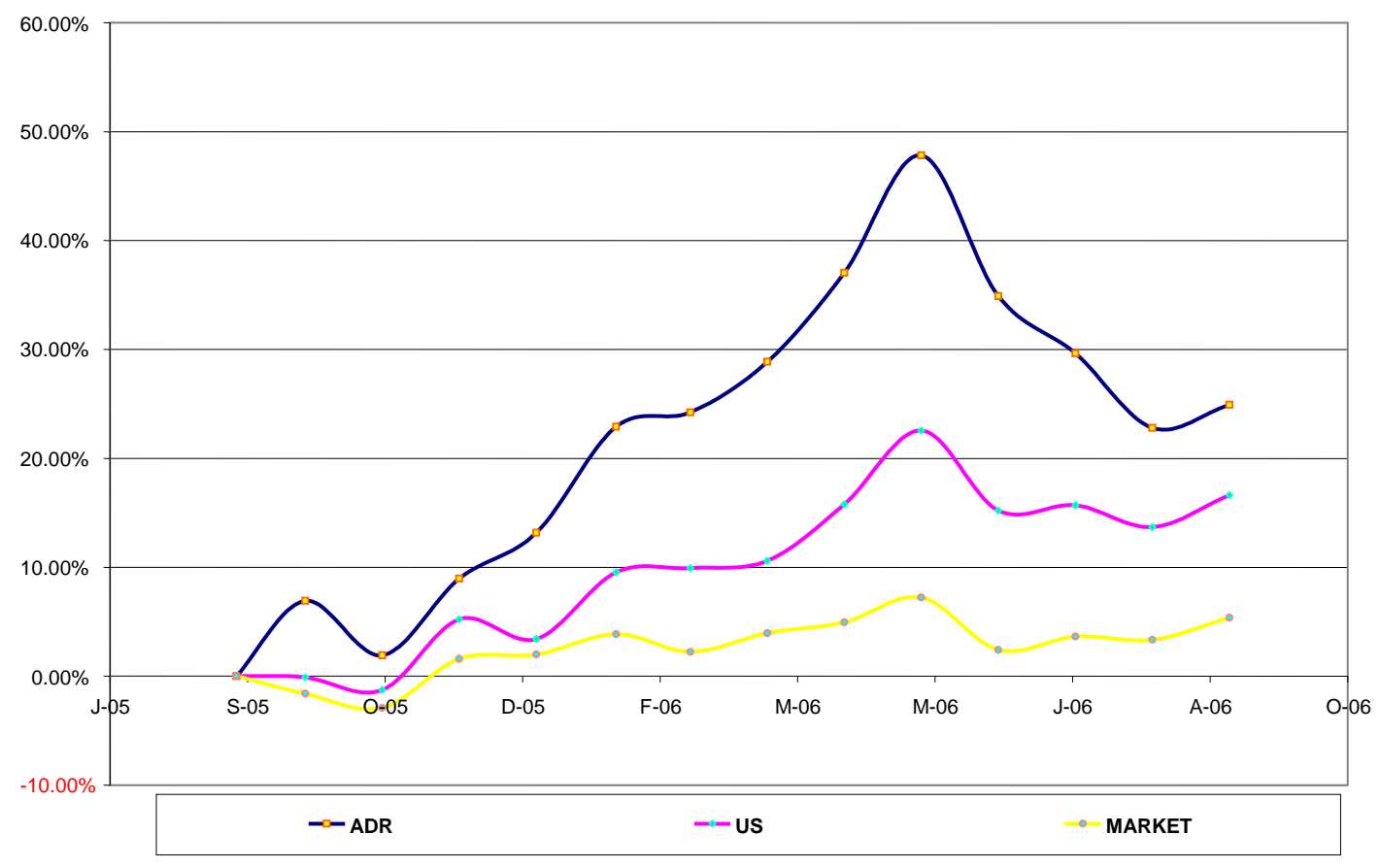

\section{THE CONCLUSIONS}

Although the American Depositary Receipt (ADR) has gained market popularity only in the last two decades, this work presents unambiguous results supporting the outstanding performance of ADRs over the past year (September 2005 to September 2006). Specifically, his study addressed the question of performance of a global portfolio versus the performance of a diversified domestic portfolio and showed that the global portfolios consistently and significantly outperformed the US equity portfolios. These results are based on data from March 2003 to September 2006. The results were striking. To be precise, they show that from September 2005 to September 2006 the return of the ADR portfolio was 20.96 percent higher than the return of the S\&P 500. Also, during the same period, the return of the ADR portfolio was 14.3 percent higher than the return of a portfolio of U.S. stocks.

\section{QUALIFICATIONS}

It is important to note that the outcome of this research is specific to the assets that were included in each portfolio and during the period in which this study was conducted. Due to changing economic conditions in the U.S. and throughout the world, the results may be different for future portfolios. In addition, as the ADR market becomes more developed, such significant gains may not last due to greater information flow and enhanced market efficiency.

Future studies need to reexamine this question and repeat this work to confirm the consistency of our results over a longer time period. Additionally, we believe that there are many reputable global companies that either don't have an ADR listing or that have recently been listed. Thus, future studies need to include these companies in their global portfolios. 


\section{REFERENCES}

1. Ahmadi, H. and Galindo, C. (2005). Two Staged Portfolio Optimizations. Journal of Business \& Economics Research. Volume 3, number 4.

2. Ahmadi, H. and Soriano, B. C. (2003). An Analytical Technique for Determining Efficient Portfolios. American Academy of Accounting and Finance. Proceedings.

3. Ahmadi, H. (1996). Testability of Arbitrage Pricing Theory by Neural Networks. Neural Networks in Finance and Investments. Probus Publishing Company, Chicago.

4. Ahearne, A., Griever, W., and Warnock, F. (2004). Information Costs and Home Bias: an Analysis of U. S. Holdings of Foreign Equities. Journal of International Economics.

5. Dahlquist, M., Rinkowitz, L., Stulz, R., and Williamson, R. (2003). Corporate Governance and the Home Bias. Journal of Financial and Quantitative Analysis, 38, 87-110.

6. Schaub, M. (2006). Short-term Investor Wealth Effects Associated with NASDAQ-traded ADRs: the Cases of Emerging, Developed, and Regional issues. Journal of Wealth Management, v8 i4.

7. Schaub, M. and Highfield, M. (2006). Market Timing Wealth Effects of American Depository Receipts: The Cases of Emerging and Developed Market Issues. Journal of International Financial Markets, Institutions \& Money, 16, 270-282.

8. Foerster, S. R. and Karolyi, A. G. (2000). The Long-run Performance of Global Equity Offerings. Journal of Financial and Quantitative Analysis. 35.4.

9. Kao, G., Wenchi, K. C., Wei, J., and Vu, J. (1991). Risk-Return Characteristics of the American Depository Receipts. Unpublished Working Paper.

10. Fang, H. and Loo, J. C. H. (2002). Pricing of American Depository Receipts under Market Segmentation. Global Finance Journal, 13.2, 237-252.

\section{NOTES}

